\title{
Babesia cameli as a New Species infecting Camels (Camelus dromedarius) at Assiut Locality
}

Barakat Shehata Abd-Elmalek ${ }^{1 *}$, Gamal Hassan Abed ${ }^{1}$ and Ahmad Mohamad Mandour ${ }^{2}$

${ }^{1}$ Zoology Department, Assiut University, Assiut, 71516, Egypt

${ }^{2}$ Parasitology Department, Assiut University, Assiut, 71516, Egypt

\begin{abstract}
Fifty one were found to be infected (26.1\%) with B. cameli (n. sp.) from one hundred and ninety five (195) from blood samples of Camelus dromedarius examined. The light microscopy was showed that, many different stages as, ray body.

Transmission and Scanning electron microscopy were revealed that, different developmental stages of $B$. sp. were found and four different forms from the new parasite were distinguished according to the presence of abundant cytoplasmic organelles and osmiophilic bodies. In experimental infection, the new parasite of Babesia cameli was found to be transmissible to laboratory white mice.
\end{abstract}

Keywords: Cameli; Ray body; Cytoplasmic organelles; Osmiophilic bodies

\section{Introduction}

Babesiosis is vectored to humans by ticks that are ecto-parasites of rodents [1,2]. Babesia microti, a species of rodent origin, has been recognized as an agent of human babesiosis in the United States [3]. Symptoms of the disease appear between 1 to 4 weeks after a person is bitten by infected ticks. The patient suffers from a gradual onset of malaise, anorexia, fatigue, mild to moderate fever, sweats, and myalgia $[4,5]$ on classical methods. The recent description of Theileria youngi from rodents in California [6], which previously might have been assigned to B. microti based on morphology, serves as an example of the utility of DNA-based methods as a complement to microscopy and life cycle information.

Diseases transmitted by ticks are of major importance to human and animals, particularly to wildlife animals. A wide variety of tickborne diseases caused by rickettsias, arboviruses, protozoan and bacteria has been described in domestic animals [7]. Therefore, the identification of pathogens in ticks is the Wrst step to understand the epidemiology and transmission of tick-borne diseases. Babesia cameli (n. sp.) was infected Camelus dromedarius for the first time in Egypt through the present study so that; the present work aims to describe the different formes by both light and electron microscopy and to elucidate the zoonotic importance of the new parasite on the experimental animals (white rats).

\section{Material and Methods}

Out of 195 blood samples of camels (Camelus dromedarius) examined for blood protozoan parasites collected from different localities of Slaughter houses at Assiut city, Egypt (Dairout, Beni Ady, Elethamna). These freshly collected blood samples were divided in two groups one in a tube coated with EDTA, and the other in a test tube for Centrifugation to obtain sera. Thick and thin blood smears were made for morphological examination of some protozoan blood parasites. Electron microscopic studies.

\section{TEM}

Few drops from blood which is highly infected with Babesia immediately fixed in $3 \mathrm{ml}$. of $3 \%$ glutaraldehyde solution in phosphate buffer ( $\mathrm{PH} 7.2$ ), for 24 hours and Kept at $4^{\circ} \mathrm{C}$ in refrigerator. The samples were post fixed in $1 \%$ Osmium tetroxide in phosphate buffer (PH 7.2, $300 \mathrm{mom}$ ), for 30 minutes. They were washed several times with phosphate buffer solution. The samples were then embedded in Epon which can preserve in structure from distortion during processing then ultra-thin sections were cut by an Ultra microtome and examined by JEOL, 100 CXII operating at $80 \mathrm{KV}$ (TEM).

\section{SEM}

For scanning electron microscope of blood; few drops were fixed in 3\% Glutaraldehyde in buffer for 24 hours. Specimens were washed three times in Phosphate buffer and post fixed in 1\% Osmium tetroxide for 2 hours and then washed in the same buffer. They were Dehydrated in different grades of ethyl alcohol and then mounted on special holders and coated with gold. Then they were examined in a JSM-T $200 \mathrm{~L} . \mathrm{V}$. 5400 Scanning Electron Microscopy (SEM).

\section{Experimental infection}

One group of laboratory animals representing in five white rates were injected with freshly infected blood camels by doses $3 \mathrm{ml}$ blood which was infected with the new parasite of Babesia cameli to examine the zoonotic importance for this parasites. Blood examination was performed daily for determine the infection of these laboratory animals.

\section{Results}

Babesia cameli (n. sp.) was infected the camels in a heavy infection in and outside the red blood corpuscles. The light microscopy was showed that, many different stages in and outside of the red blood

*Corresponding author: Abd-Elmalek BS, Faculty of Science, Zoology Department Assiut University, Assiut, 71516, Egypt, Tel: 0201113532752; Fax: 002088342708; E-mail: barakatshehata@yahoo.co

Received March 01, 2016; Accepted September 06, 2016; Published September 12, 2016

Citation: Abd-Elmalek BS, Abed GH, Mandour AM (2016) Babesia cameli as a New Species infecting Camels (Camelus dromedarius) at Assiut Locality. J Diabetes Metab 7: 700. doi: 10.4172/2155-6156.1000700

Copyright: ㄷ 2016 Abd-Elmalek BS, et al. This is an open-access article distributed under the terms of the Creative Commons Attribution License, which permits unrestricted use, distribution, and reproduction in any medium, provided the original author and source are credited. 
Citation: Abd-Elmalek BS, Abed GH, Mandour AM (2016) Babesia cameli as a New Species infecting Camels (Camelus dromedarius) at Assiut Locality. J Diabetes Metab 7: 700. doi: 10.4172/2155-6156.1000700

corpuscles as, free trophozoite outside of the red blood corpuscles (Figure 1), ray body in the red blood corpuscles (Figure 2) and other stages (Figures 3 and 4 ). The infection with this parasite sometimes was accompanied by Theileria sp.

Transmission electron microscopy revealed that, different developmental stages of $B$. sp. were found, rounded or oval shaped trophozoites measured $(1.58 \times 1.25 \mu \mathrm{m})$ in diameter. The body was covered by a single membrane; one prominent nucleus was observed and measured $(1 \times 0.41 \mu \mathrm{m})$ in diameter, well developed rough endoplasmic reticulum, some vacuoles and numerous free ribosomes (Figure 5).

Some trophozoites were presented with a single cytostome composed of a single electron-dense concentric ring, with an internal diameter of $(0.3 \times 0.076 \mu \mathrm{m})$ and located on the periphery of the parasite. Small intra-cytoplasmic food vacuoles were observed next to the cytostome. One of these vacuoles was contained material of similar density to hemoglobin.

Among these parasites was located outside the erythrocytes, two morphologically distinct types were observed. Some were presented with abundant cytoplasmic organelles, especially osmiophilic bodies which are oval or elongated electron-dense structures (Figure 6). In the other, the amount of organelles in the cytoplasm was significantly reduced (Figure 7).

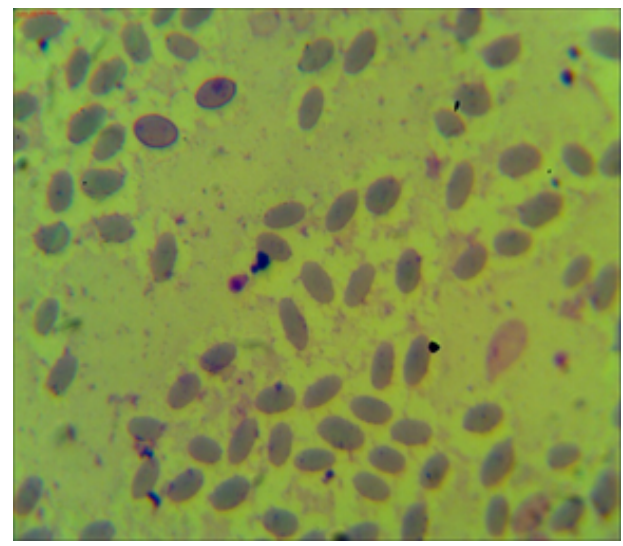

Figure 1: Photomicrograph showing trophozoite of Babesia cameli. (B) outsid of the red blood cells of Camelus dromedarius stain with Geimsa stain.

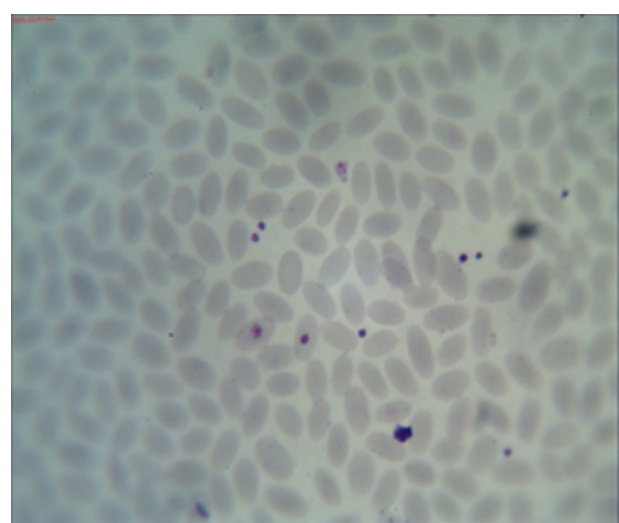

Figure 2: Photomicrograph showing ray body $(\mathrm{Rb})$ of $B$. cameli. In the red blood cells of Camelus dromedarius stain with Geimsa stain

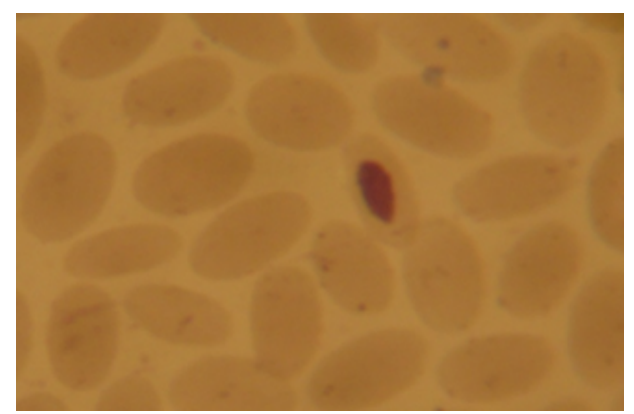

Figure 3: Photomicrograph showing kinete of $B$. cameli. in the red blood cells of Camelus dromedarius stained with Geimsa stain.

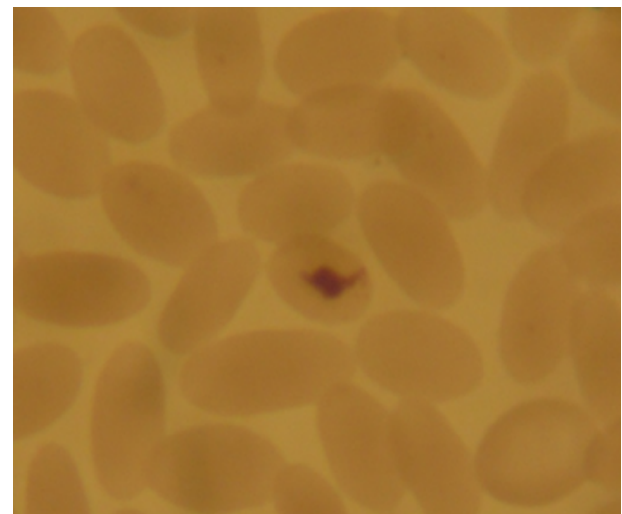

Figure 4: Photomicrograph showing gametogenesis of $B$. cameli. in the red blood cells of Camelus dromedarius stained with Geimsa stain.

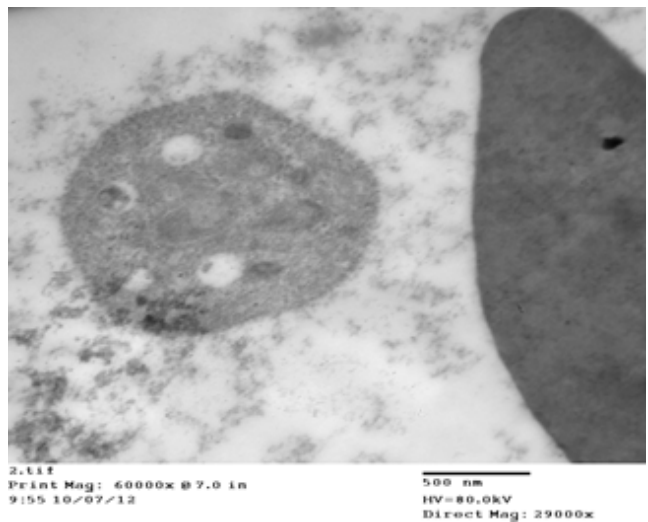

Figure 5: Transmission electron micrograph of the first form of Babesia cameli. Showing cytostome (c), rough endoplasmic reticulum (RER) and vacuoles $(\mathrm{V})$.

Both parasite forms were surrounded by a single membrane and an electron-lucent, circular region and sometimes limited by a membrane. This vacuolated area in the parasite cytoplasm was contained a large amount of microtubules denoted as bright bodies. Microtubules running parallel to the cytoplasmic membrane or extending in cytoplasmic projections came out of this area. The only visible areas in the rays were varying numbers of microtubules parallel to the entire structure which is delimited by a membrane.

Also TEM revealed that, presence of another type $B$. sp. which was 
Citation: Abd-Elmalek BS, Abed GH, Mandour AM (2016) Babesia cameli as a New Species infecting Camels (Camelus dromedarius) at Assiut Locality. J Diabetes Metab 7: 700. doi: 10.4172/2155-6156.1000700

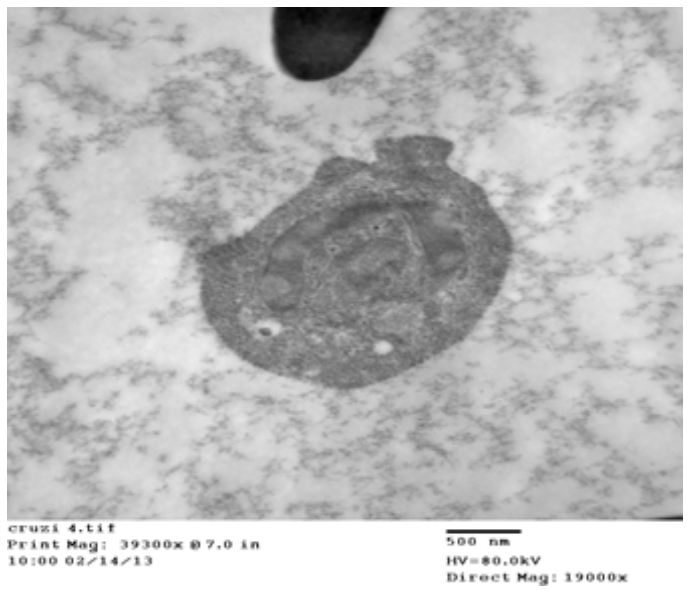

Figure 6: Transmission electron micrograph of the second form Babesia sp,showing cytostome (c), bright body $(\mathrm{Bb})$, elongated electron dense structure (EEDS) and micropore (Mp).

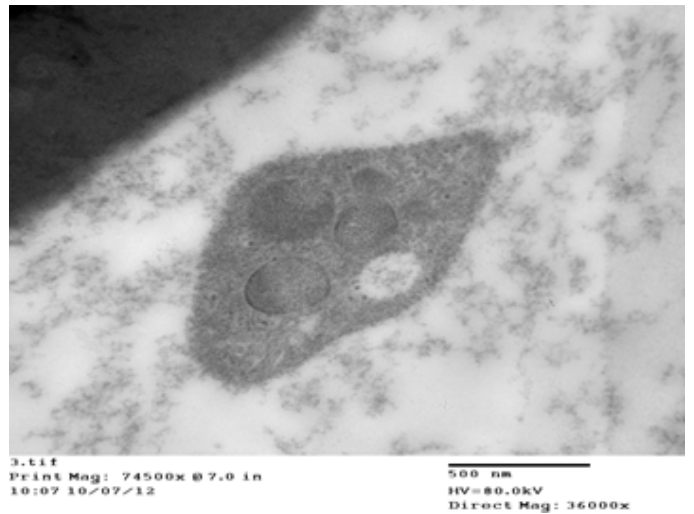

Figure 7: Transmission electron micrograph of the third form Babesia cameli. showing, an osmiophilic body (OS. b) and large vacuole (LV).

elongated or oval in shape and measured $(3.2 \times 1.7 \mu \mathrm{m})$ (Figure 8$)$. It had thicker and more electron-dense walls due to deposition of granules on its surface and presence of pores on the surface of erythrocytes. No nuclear fusion was observed. Small numbers of micropores were observed (Figure 9).

Scanning electron microscopy showed that, $B$. sp. with a tubular structure which was contact with the erythrocyte (Figure 10). Supporting the first form of $B$. sp. Also presence of $B$. sp. and more clefts in the infected blood corpuscles (Figure 11) due to its infected by $B$. sp.

\section{Discussion}

By compared the ultrastructure of $B$. equi trophozoites which was isolated in Minas Gerais, Brazil [8] with the first form of $B$. sp. infected Camelus dromedarius in the present study was found that, presence of food vacuoles, endoplasmic reticulum and the tubular structure as feeding mechanism in the two species supported with transmission and scanning electron microscopy in the present study.

Also mitochondrial organelles were not observed in the intraerythrocytic stages of $B$. equi and typical mitochondria have not been recorded in any previous studies [9-14]. A singular aspect of the morphology of the B. equi trophozoites in the presence of a cytostome and the tubular feeding structure involved in the feeding mechanism [15] suggesting that the first form in the present study was B. equi.

Presence of bright bodies and electron- dense organelles in the cytoplasm of the parasite among them the osmiophilic bodies in two forms of $B$. sp. in the present study was similar to a large extent with description of the ultrastructure of gametes of B. bigemina was obtained "in vitro" red cell culture [16,17].

The structure observed were similar to these were described by Mehlhorn et al. [16] and Ribeiro et al. [18]. At the same time when was compared the last form of $B$. sp. in the present study with its thick membrane electron-dense agree with that, $B$. caballi which its infection originated from horses [4] where the forms found in gut cells of Anocentor nitens ticks.

\section{Conclusion}

Babesia sp. for the first time was infected Camelus dromedarius at Assuit locality, Upper Egypt. The new parasite can infected rats experimentally. At the same time it was affected on the tissues of the

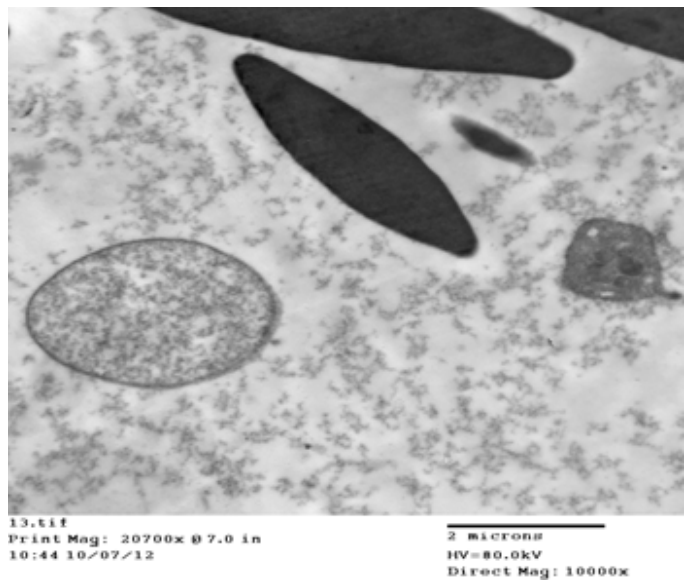

Figure 8: Transmission electron micrograph of the forht form Babesia cameli. showing more electron dense walls (Edw) in Camelus dromedarius.

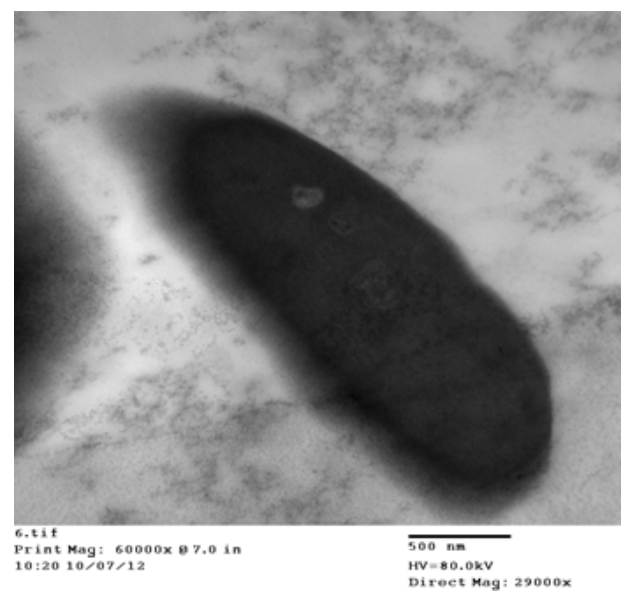

Figure 9: Transmission electron micrograph of pores $(\mathrm{Po})$ in the surface of red blood cells of Camelus dromedarius due to its infected with Babesia cameli. Transmission electron micrograph of pores $(\mathrm{Po})$ in the surface of red blood cells of Camelus dromedarius due to its infected with Babesia cameli. 
Citation: Abd-Elmalek BS, Abed GH, Mandour AM (2016) Babesia cameli as a New Species infecting Camels (Camelus dromedarius) at Assiut Locality. J Diabetes Metab 7: 700. doi: 10.4172/2155-6156.1000700

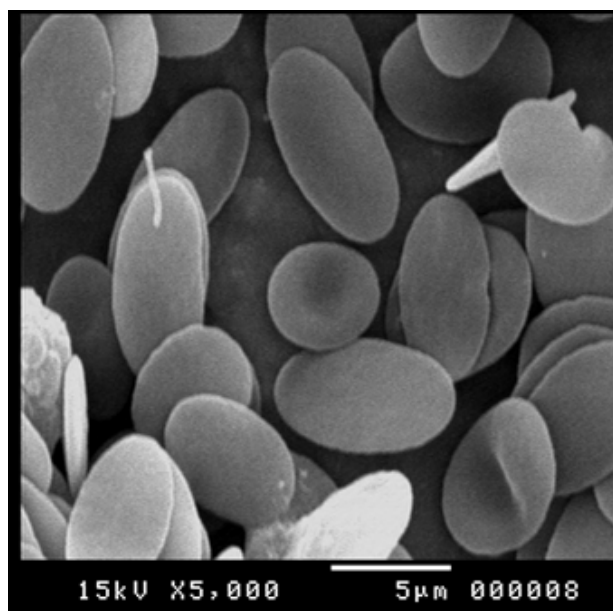

Figure 10: Scanning electron micrograph of red blood cells of Camelus dromedarius showing tubular structure (TS) of $B$. cameli.

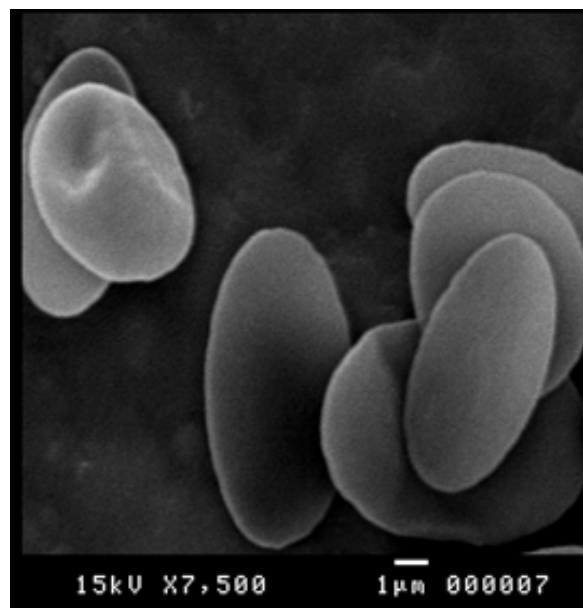

Figure 11: Scanning electron micrograph of red blood cells of Camelus dromedarius showing clefts in rbcs due to its infected with $B$. cameli.

infected rats and their hematological parameters as (Rbcs, Wbcs, $\mathrm{Hb}$, $\mathrm{Ht}, \mathrm{Mch}, \mathrm{Mchc}$ and Mcv.

\section{References}

1. Levine ND (1971) Taxonomy of the piroplasms. Trans Am Microsc Soc 90: 2-33.

2. Telford SR, Gorenflot A, Brasseur P, Spielman A (1993) Babesial infections in humans and wildlife parasitic protozoa. Academic Press Inc 5: 1-47.
3. Dammin GJ, Spielman A, Benach JL, Piesman J (1981) The rising incidence of clinical Babesia microti infection. Hum Pathol 12: 398-400.

4. Ruebush TK, Juranek DD, Chisholm ES, Snow PC, Healy GR, et al. (1977) Humanbabesiosis on Nantucket Island, evidence for self-limited and subclinical infections. N Engl J Med 297: 825-827.

5. Ruebush TK, Cassaday PB, Marsh HJ, Lisker SA, Voorhees DB, et al. (1977) Human babesiosis on Nantucket Island: clinical features. Ann Intern Med 86: 6-9.

6. Kjemtrup AM, Robinson T, Conrad PA (2001) Description and epidemiology of Theileria youngi $n$. sp. from a northern Californian dusky-footed wood rat (Neotoma fuscipes) population. J Parasitology 87: 373-378.

7. Sonenshine DE (1993) Biology of Ticks Oxford University Press. New York

8. Guimaraes AM, Lima JD, Ribeiro MFB (2003) Ultrastructure of Babesia equi trophozoites isolated in Minas Gerais, Brazil. Pesq Vet Bras 23: 101-104.

9. Simpson CF, Kirkhan WW, Kling JM (1967) Comparative morphologic features of Babesia caballi and Babesia equi. Am J Vet Res 28: 1693-1697.

10. Simpson CF (1970) Electron microscopic comparison of Babesia sp. And hepatic changes in ponies and mice. Am J Vet Res 31: 1763-1768.

11. Simpson CF, Neal FC (1980) Ultrastructure of Babesia equi in ponies treated with imidocarb. Am J Vet Res 41: 267-271.

12. Frerichs WM, Holbrook AA (1974) Feeding mechanisms of Babesia equi. J Protozool 21: 707-709.

13. Ribeiro MFB, Guimares AM (1998) Encephalitozoon-like microsporodiain the ticks Amblyomma cajennense and Anocentor nitens (Acari:Ixodidae). J Med Entomol 35: 1029-1033.

14. Weber G, Friedhoff KT (1977) Preliminary observations on the ultrastructure of suppossed sexual stages of Babesia bigemina (Piroplasmea). Z Parasitenkd 25: 83-92.

15. Mehlhorn H, Schein E, Voigt WP (1980) Light and electron microscopic study on developmental stages of Babesia canis within the gut of the tick Dermacentor reticulatus. J Parasitol 66: 220-228.

16. Mehlhorn H, Moltmann U, Schein E, Voigt WP (1981) Fine structure of supposed gametes and syngamy ofBabesia canis (Piroplasmea) after in-vitro development. Zentralbl Bakteriol Mikrobiol Hyg A 250: 248-255.

17. Droleskey RH, Mercer SH, DeLoach JR, Craig TM (1993) Ultrastructure of Hepatozoon canis in the dog. Veterinary Parasitology 50: 83-99.

18. Ribeiro FB, Passo MF (2006) Natural co-infection of Babesia caballi and Encephalitozoon-like microsporidia in the tick Anocentor nitens (Acari: Ixodidae). J. of Invert. Pathol 93: 183-185 